Perla Klautau

\title{
Avançando para trás: a presença do legado de Ferenczi nas teorias de Winnicott e Lacan
}

\section{Tese de Doutorado}

Tese apresentada ao Programa de Pós-Graduação em Psicologia Clínica na PUC-Rio como requisito parcial para obtenção do título de Doutor em Psicologia Clínica.

Orientador: Octavio Almeida de Souza - PUC-Rio 
Perla Klautau

\section{Avançando para trás: a presença do legado de Ferenczi nas teorias de Winnicott e Lacan}

Tese de Doutorado

Tese apresentada como requisito parcial para obtenção do grau de Doutor em Psicologia Clínica pelo Programa de PósGraduação em Psicologia Clínica na PUC-Rio. Aprovada pela Comissão Examinadora abaixo assinada.

Prof. Octavio Souza - PUC-Rio - Orientador

Prof. Mario Eduardo - UNICAMP

Prof. Daniel Kuperman - USP

Prof. Silvia Zornig - PUC-Rio

Prof. Ana Beatriz Freire - UFRJ

Paulo Fernando Carneiro de Andrade - Coordenador do centro de teologia e ciências humanas da PUC-RIO.

Rio de Janeiro, 09 de março de 2007-07-03 
Todos os direitos reservados. É proibida a reprodução total ou parcial do trabalho sem autorização do autor, do orientador e da universidade.

Klautau, Perla

Graduou-se em Psicologia na Pontificia Universidade Católlica do Rio de Janeiro. Em 2002, concluiu o curso de mestre em Psicologia Clínica na Pontifícia Universidade Católica sob a orientação do professor Octavio Souza com a dissertação "Encontros e desencontros entre Winnicott e Lacan".

Ficha Catalográfica:

Avançando para trás: a presença do legado de Ferenczi nas teorias de Winnicott e Lacan / Perla Klautau ; orientador: Octavio Almeida de Souza. - 2007.

111 f. : il. ; $30 \mathrm{~cm}$

Tese (Doutorado em Psicologia)-Pontifícia Universidade Católica do Rio de Janeiro, Rio de Janeiro, 2007.

Inclui bibliografia

1. Psicologia - Teses. 2. Limites de interpretação. 3. Transferência como experiência do vivido. 4. Freud. 5. Ferenczi. 6. Winnicott. 7. Lacan. I. Souza, Octavio Almeida de. II. Pontifícia Universidade Católica do Rio de Janeiro. Programa de PósGraduação em Psicologia. VI. Título. 


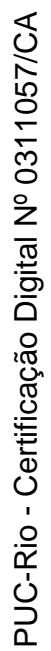

Para Fernando, Elena e Bernardo. 


\section{Agradecimentos}

A meu orientador, Octavio Souza, pelo ensino criativo que tanto me inspira e pelo exemplo a ser seguido.

A Benilton Bezerra Jr. e Carlos Lannes, pela parceria, pela amizade e pelas generosas contribuições.

A Cláudia Garcia, pela clareza e pela objetividade que sempre permeiam nossas conversas.

A todos os participantes do seminário Encontros e desencontros entre Winnicott e Lacan, pelas discussões que estão presentes em grande parte deste trabalho.

Aos mais próximos: Bia, Dani, Carla e Marcelo, pela companhia; a Fernanda, Suzana, Sara, Patrícia, Inês, Mariane, Márcio e José Octavio, pela permanência dos nossos laços.

A Ana, Karla e Marco, sempre carinhosos e dispostos a ajudar. Ao Marco, sobretudo, pela ajuda imprescindível nos momentos finais e pela revisão cuidadosa do texto.

A minha imensa gratidão ao Alexandre, a toda sua família - Maria Conceição, Marçal, Conceição e Judite - e a Marlene, por terem cuidado tão bem do Bernardo nos momentos em que não pude estar presente para me dedicar a este trabalho.

Aos professores e funcionários do departamento.

A CAPES e a PUC-Rio, pelos auxílios concedidos. 


\section{Resumo}

Klautau, Perla; Souza, Octavio. Avançando para trás: a presença do legado de Ferenczi nas teorias de Winnicott e Lacan. Rio de Janeiro, 2007, 111 páginas da tese, Tese de doutorado -

Departamento de Psicologia, Pontifícia Universidade Católica do Rio de Janeiro.

O objetivo desta tese é o de sugerir a inclusão de Lacan - mais precisamente, da última parte de seu ensino - na tradição ferencziana, junto com a figura de Winnicott, cuja filiação ao psicanalista húngaro já é reconhecida por boa parte da comunidade psicanalítica. O pano de fundo desta investigação são os desafios impostos pelos quadros psicopatológicos que conduzem o fazer analítico aos limites do interpretável. Para sustentar a tese que norteia este trabalho, primeiramente será abordada a valorização, efetuada por Ferenczi durante a década de 1920, do vivido no seio da experiência analítica movimento que o levou à exploração das fases mais precoces do desenvolvimento humano. Em seguida, será examinado o modo como Winnicott (desde sempre) e Lacan (tardiamente) tematizaram os primórdios da vida psíquica e a dimensão pré-discursiva da experiência subjetiva. Por último, será discutida como a valorização do âmbito da experiência não organizada lingüisticamente repercute nas formulações clínicas destes dois herdeiros. Ao final deste percurso pretende-se evidenciar a proximidade entre a clínica do holding e a clínica da nodulação, e a presença nelas do legado ferencziano.

\section{Palavras-Chave}

Limites da interpretação, transferência como experiência do vivido, Freud, Ferenczi, Winnicott e Lacan. 


\section{Résumé}

Klautau, Perla; Souza, Octavio. Marcher em avant et faire marche arrière: des limites de línterpretation à la valorisation du vécu dans l'expérience analytique. Rio de Janeiro, 2007, 111 pages, Thèse doctorat - Dèpartament de Psychologie, Pontifícia Universidade Católica do Rio de Janeiro.

L'objectif de cette thèse est de suggérer l'inclusion de Lacan - plus précisément, de la dernière partie de son enseignement - dans la tradition ferenczienne, à côté de la figure de Winnicott, dont la filiation au psychanalyste hongrois est déjà reconnue par une grande partie de la communauté psychanalytique. L'arrière-fond de cette investigation, ce sont les défis posés par les cadres psychopathologiques qui poussent le faire analytique aux limites de ce qui peut être interprété. Pour soutenir la thèse qui est le nord de ce travail, on va traiter premièrement de la valorisation, effectuée par Ferenczi aux cours des années 1920, de ce qui a été vécu au sein de l'expérience psychanalytique mouvement qui l'a conduit à l'exploration des phases plus précoces du développement humain. Ensuite, on va examiner comment Winnicott (depuis toujours) et Lacan (plus tard) ont thématisé la vie psychique primordiale et la dimension pré-discursive de l'expérience subjective. Finalement, on va discuter comment la valorisation du cadre de l'expérience non-organisée linguistiquement se fait-il l'écho des formulations cliniques de ces deux héritiers. Au bout de ce parcours, on a l'intention d'exhiber la proximité entre la clinique du holding et la clinique de la nodulation, et encore la présence en eux de l'héritage ferenczien.

\section{Mots-clé}

Limites de l'interprétation, transfert comme expérience du vécu, Freud, Ferenczi, Winnicott e Lacan. 


\section{Sumário}

1. Introdução

2. Capítulo 1 - Dos limites do interpretável à valorização do vivido na clínica psicanalítica

3. Capítulo 2 - Avançando para trás 31

3.1 Capítulo 2.1 - O vivido na teoria winnicottiana: o campo 33 dos objetos subjetivos

3.2 Capítulo 2.2 - O vivido na teoria lacaniana: o campo

pré-discursivo

4. Capítulo 3 - Os reflexos clínicos do avanço para trás 76

4.1. Capítulo 3.1 - Clínica do Holding 76

4.2. Capítulo 3.2 - Clínica da nodulação 90

5. Considerações finais 103

$\begin{array}{ll}\text { 6. Bibliografia } & 106\end{array}$ 